\title{
Development of a Manually Operated Hydraulic Cattle Feed Block Making Machine
}

\author{
U.P. Kaushalya ${ }^{1}$, P.D. Kahandage ${ }^{1}$ and W.A.D. Nayananjalie ${ }^{2 *}$
}

${ }^{1}$ Department of Agricultural Engineering and Soil Science, Faculty of Agriculture, Rajarata University of Sri Lanka, Anuradhapura, Sri Lanka

$2^{*}$ Department of Animal and Food Sciences, Faculty of Agriculture, Rajarata University of Sri Lanka, Anuradhapura, Sri Lanka

Correspondence:

2 nayananjalie@yahoo.com

ORCID:0000-0002-5225-0074

\begin{abstract}
Feed blocks, which are made by improving the nutritional status of agricultural by-products, are a proved solution to uplift the productivity of dairy animals in Sri Lanka. Though feed block making machines are locally available, their prices are unaffordable for small-scale rural farmers. Therefore, the objective of this study was to introduce an efficient and affordable feed block making machine for smallscale farmers. The newly fabricated machine consisted of hydraulically operated jack, mould and a piston fixed to an iron frame. The total cost of production was 43,000 LKR. Feed blocks were produced with the new machine using two separate mixtures of ingredients with four different compaction times. Mixture 1 contained $10 \%$ molasses apart from other ingredients and without cement, whereas mixture 2 replaced $5 \%$ of molasses with cement. The suitable compaction time for the mixture 1 and mixture 2 were 15 minutes and 10 minutes, respectively at 19265 $\mathrm{kN} \mathrm{m} \mathrm{m}^{-2}$ maximum pressure. The actual capacity of the machine for mixture 1 prepared with 15 min compaction time was 3 blocks h${ }^{-1}$, while it was 4 blocks h-1 for the mixture 2 prepared with $10 \mathrm{~min}$ compaction time irrespective to the gender. The post-compression expansion and durability of mixture 1 were $23.73 \%$ and $99.64 \%$, respectively while the corresponding figures for mixture 2 were $18.64 \%$ and $99.82 \%$. No change could be observed in appearance, colour and odour of the feed blocks within 30 days of storage. According to the results, this new machine is affordable to small-scale farmers and it can be successfully used to produce feed blocks for cattle.
\end{abstract}

Keywords: Cattle feed block, Durability, Post compression expansion 


\section{Introduction}

One of the major reasons for the reported low milk production in Sri Lanka is poor nutrition of dairy cows. This is influenced by seasonal fluctuations of roughages resulting in acute shortage of feed resources, the high price of compounded feeds and lack of knowledge on methods of low-cost feed supplementation (Perera and Jayasuriya 2008). To improve the performance of dairy animals, supply of sufficient nutrients is needed and cattle feed block is one of the best and easiest solutions to overcome this problem.

Cattle feed block is a solid brick consisting of ingredients such as molasses, non-protein nitrogen (NPN), rumen by-pass protein, minerals, lipids, dry forages, industrial byproducts, etc. Advantages of feed blocks can be listed as appropriate supplementation for poor quality roughages and thereby increased feed intake, increased dry matter digestibility, higher milk yield, improved reproductive efficiency and stimulated growth rates (Makkar 2006). These feed blocks can be produced manually or mechanically. The manual method involves three main steps viz., mixing of feed ingredients, pressing the mixture into a mould, drying in the open sun followed by packaging. However, this is time consuming and labour intensive method results in low in quality of the feed blocks produced (Mohammed 2007; Anon 2012; Lohan 1995).

Commercial level semi-automatic cattle feed block making machines are available in Sri Lanka. These machines produce $2 \mathrm{~kg}$ feed blocks $(20 \mathrm{~cm} \times 20 \mathrm{~cm} \times 11 \mathrm{~cm})$ using hay with a capacity of about 100 blocks per hour (Silva 2017). Although, these types of machines are not popular in Sri Lanka, a wide range of similar machines with various capacities and efficiencies are popular among Indian farmers (Anon 2012; Singh 2007). However, attention was paid to introduce a hydraulic cattle feed block making machine with the principle of hydraulic press invented by a well-known scientist Joseph Bramah in 1975, in order to popularize the feed block making in Sri Lanka.

The land area under livestock farming in Sri Lanka is reported to be around 0.56 million ha, out of which $99 \%$ of it comes under smallholdings (Perera and Jayasuriya 2008). Although almost all the dairy farms yield milk below the potential capacity, farmers have less intention to produce feed blocks for a better and balanced supply of nutrients. The reason behind this is the absence of suitable machines within the affordable limits of cattle farmers. To overcome this problem, an affordable, efficient and durable cattle feed block making machine is required. With the invention of an appropriate machine, profitability of the dairy industry would be increased by a continuous supply of nutritious feedstuff for dairy animals. Further, this can reduce time and labour requirement by enhanced quality of feed blocks. Therefore, this study aimed at the fabrication of a small-scale cattle feed block making machine, especially for small-scale dairy farmers to produce feed blocks locally to fulfil the nutrient requirement. 


\section{Materials and Methods}

\section{Design of the Machine}

\section{Design concepts and considerations}

Design, selection of materials and fabrication were based on the following concepts.

i. Proper attention was given for the provisions for adjustments such as filling the material into the mould and removing prepared block out easily.

ii. The hydraulic jack was designed to operate manually to facilitate the operation in rural areas even without electricity supply while reducing the operational cost.

iii. Locally available standard materials were used to ensure easy repair and maintenance in remote areas.

\section{Development procedure of the machine}

Following flow chart (Fig. 1) was used to examine and overcome any possible theoretical or practical problems in developing the machine.

The finalized design of the cattle feed block making machine is shown in Fig. 2. The major element of the machine was a normal upward hydraulic jack with a maximum capacity of 500 $\mathrm{kN}$ to provide the required force to compress feeding materials. The other components of the machine were mould and its holder, movable piston, piston moving handle and the frame.

\section{Construction of the Machine}

Availability, suitability and the cost of the materials were the major factors that considered when selecting the materials for the design (Khurmi and Gupta, 2006).

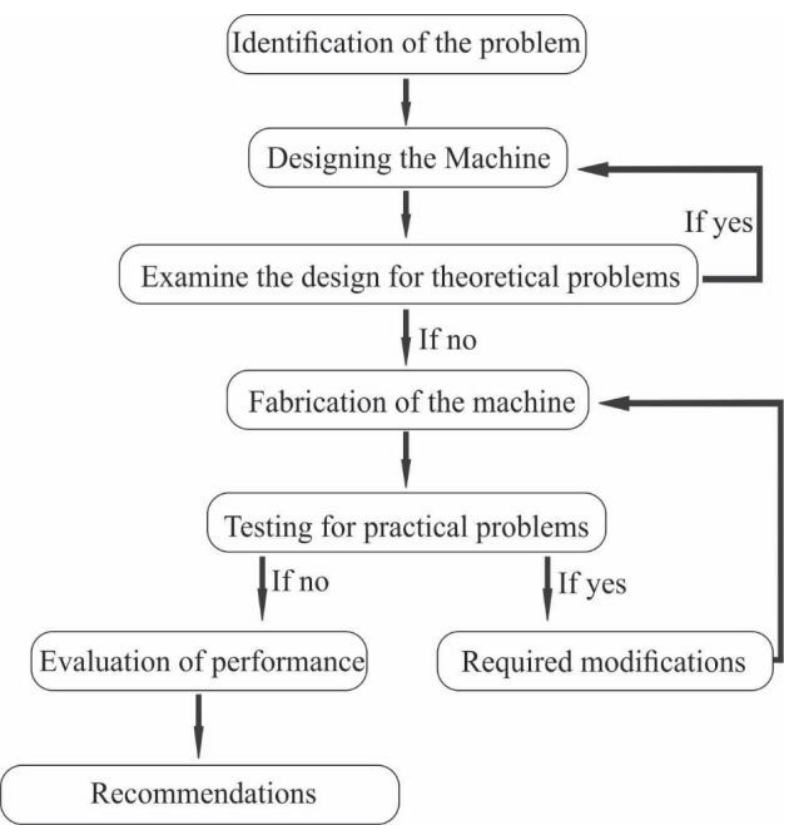

Figure 1: Unit operations of the development of cattle feed block making machine

Therefore, several criteria were considered when selecting the materials for the feed block making machine and used materials and their selection criteria were summarized in Table 1.

The frame was the supporting structure which assembled all other parts and strong enough for any working condition while providing moving and adjusting paths. Mild steel U channel bars (75 $\mathrm{mm} \times 37.5 \mathrm{~mm} \times 37.5 \mathrm{~mm}$ ) were used to construct the frame of the machine. Dimensions of the frame were $120 \mathrm{~cm} \mathrm{x} 37 \mathrm{~cm}$ x $7.5 \mathrm{~cm} \mathrm{(H} \mathrm{x}$ L x W).

Mould was constructed by drilling a MS iron shaft which gave the specific shape of feed block by holding the feeding material at the time of compress. Height and diameter of the mould was $30 \mathrm{~cm}$ and $18 \mathrm{~cm}$, respectively giving nearly $7000 \mathrm{~cm}^{3}$ capacity. 


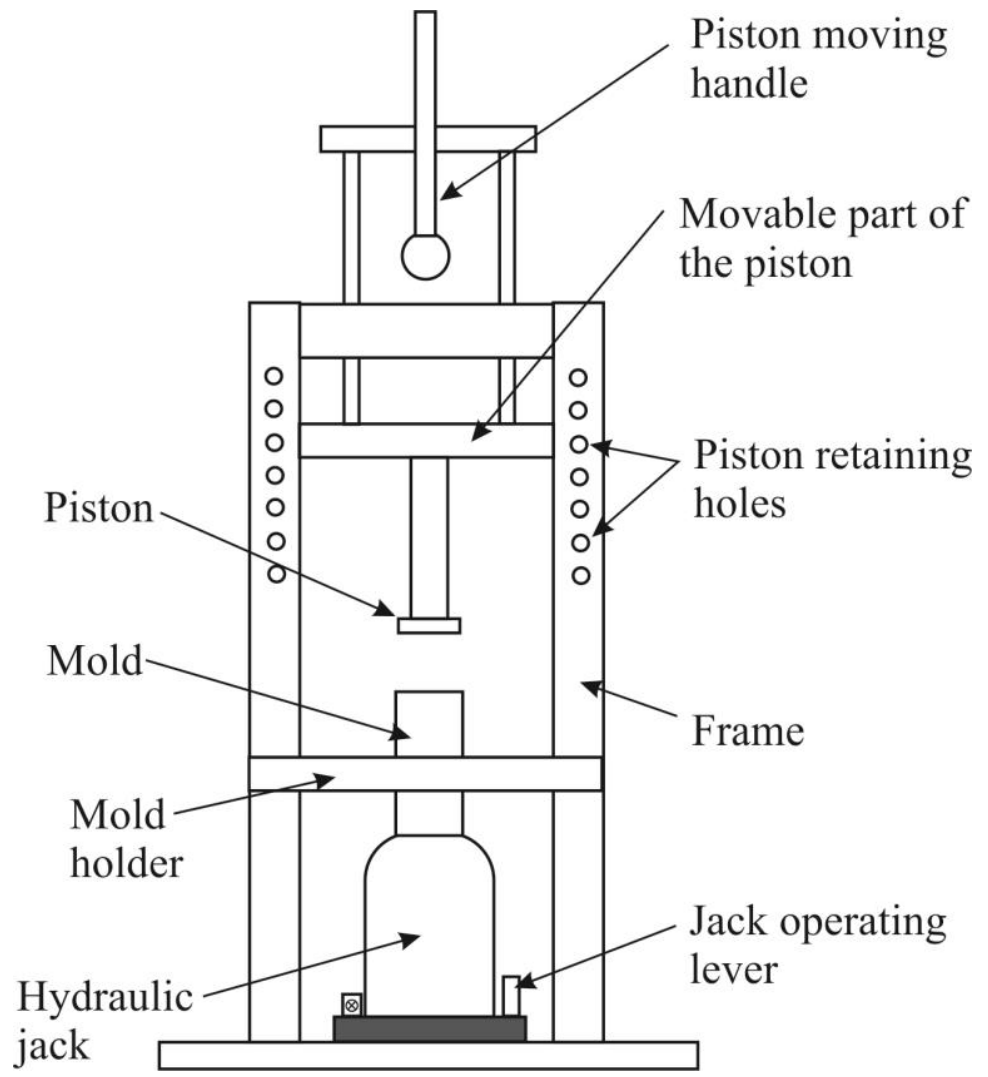

Figure 2: Schematic representation of major components of the machine

Table 1: Materials used in feed block making machine and selection criteria

\begin{tabular}{lll}
\hline Component & Used material & Criteria for material selection \\
\hline Machine frame & Mild steel (MS), U channel bars & Strength, stability/ rigidity \\
Mould & Mild steel shafts & Strength, workability, corrosion resistance \\
Mould holder & Mild steel L iron & Strength, lightness, formability \\
Piston & Mild steel L iron, Mild steel box bars & Strength, lightness, formability \\
Piston moving handle & Galvanized iron & Strength, corrosion resistance, workability, lightness, cost \\
\hline
\end{tabular}

The piston was designed to compact the feeding materials with the force of hydraulic jack and it was inserted into the mould at the upper end. The piston moved vertically along the frame and facilitated filling ingredients and removing blocks out. It was constructed by L iron bars (50 mm x $50 \mathrm{~mm}$ ) attached with $1.5 \mathrm{~cm}$ thick circular iron plate at the lower end of the piston. The piston was connected with the piston moving handle and it was made of GI pipes. 


\section{Evaluation of Machine}

\section{Preparation of feed mixtures}

The mechanical performance of the fabricated feed block making machine was evaluated with two different feed blends as mixture 1 and mixture 2. The compositions of mixtures are given in Table 2 (Kulathunga et al. 2015).

Table 2: Composition of the feed mixtures

\begin{tabular}{lcc}
\hline Ingredients & Mixture 1 (\%) & Mixture 2 (\%) \\
\hline Straw & 65 & 65 \\
Rice bran & 10 & 10 \\
Coconut poonac & 10 & 10 \\
Molasses & 10 & 5 \\
Cement & - & 5 \\
Urea & 2 & 2 \\
Salt & 2 & 2 \\
Di-Calcium & 0.5 & 0.5 \\
Phosphate & & \\
Lime & 0.5 & 0.5
\end{tabular}

In brief, paddy straw was chopped into small pieces $(1.5 \mathrm{~cm}-2.0 \mathrm{~cm})$ and coconut poonac, rice bran and urea were ground into a powder. Molasses was heated up to $70{ }^{\circ} \mathrm{C}$ to facilitate uniform application after which, all raw ingredients were weighted separately as given in Table 2. Then paddy straw, coconut poonac and rice bran were mixed thoroughly followed by dissolving all other micronutrients in molasses. Finally, molasses and straw blends combined and mixed well.

\section{Determination of suitable compaction time}

Both mixtures contained very less amount of moisture and the machine was manually operated. Therefore, blocks should be kept sometimes under the provided pressure for better compaction. To check the most appropriate post-compaction time, feed blocks were compacted under four different time durations (5 minutes, 10 minutes, 15 minutes and 20 minutes).

\section{Treatments}

The treatments were formed in a two-factor factorial arrangement. Type of feed mixture was considered as one factor and postcompression time was the second factor which had four levels. Together there were eight treatments as follows and six blocks from each treatment were prepared.

$\mathrm{M}_{1} \mathrm{~T}_{1}$ - Mixture 1 under 5 minutes compaction $\mathrm{M}_{1} \mathrm{~T}_{2}$ - Mixture 1 under 10 minutes compaction $\mathrm{M}_{1} \mathrm{~T}_{3}$ - Mixture 1 under 15 minutes compaction $\mathrm{M}_{1} \mathrm{~T}_{4}$ - Mixture 1 under 20 minutes compaction $\mathrm{M}_{1} \mathrm{~T}_{2}$ - Mixture 2 under 5 minutes compaction $\mathrm{M}_{1} \mathrm{~T}_{2}$ - Mixture 2 under 10 minutes compaction $\mathrm{M}_{1} \mathrm{~T}_{2}$ - Mixture 2 under 15 minutes compaction $\mathrm{M}_{1} \mathrm{~T}_{2}$ - Mixture 2 under 20 minutes compaction After identifying the best two treatments, machine performances were further evaluated.

\section{Durability assessment}

Three randomly selected feed blocks from each treatment were dropped from a $2 \mathrm{~m}$ height on a concrete floor. Weight of the blocks were recorded before and after dropping and weight retained after each fall was then calculated to estimate the durability (Du) as given in the equation below (Santhiralingam and Sinniah 2018).

$$
D_{u}=\frac{M_{A}}{M_{F}} X 100
$$

Where, 
$\mathrm{M}_{\mathrm{E}}$ - Mass of the block before the drop test ( $\mathrm{g}$ )

$\mathrm{M}_{\mathrm{A}}$ - Mass of the block after the drop test (g)

\section{Post-compression expansion (PCE)}

Height of all the feed blocks were measured at the beginning and kept them for 10 days. These height measurements were repeated daily and PCE value was calculated using the following equation.

$$
\operatorname{PCE}(\%)=\left(T_{i}-T_{1}\right) / T_{1} \times 100
$$

Where,

$T_{1}$ - Height of blocks just after the compaction (1st day) (mm)

$T_{i}$ - Height of blocks at the $i^{\text {th }}$ day $(\mathrm{mm})$

\section{Calculation of mechanical performances}

After determining the suitable compaction time for each mixture, mechanical parameters such as theoretical capacity, actual capacity and efficiency were determined separately using male and female operators.

\section{Capacity of the feed block making machine}

Theoretical capacity (TC) and actual capacity (AC) of the feed block making machine were calculated as described by Hancock et al. (1991). Three male and three female operators were employed to operate the machine and three trials were conducted with each operator. Time taken to compress each block was recorded and TC was calculated using the following equation.

TC (blocks h-1) $=3600$ (sec. $/ \mathrm{h}) / \mathrm{t}$ (sec./block)

Where, $t$ is the time taken for completely prepare a block.
To calculate the $\mathrm{AC}$, the number of feed blocks prepared by each operator (three male and three female) was recorded considering the time taken for loading, unloading, adjustments, worker fatigue, etc.

AC $($ blocks h-1) $=$ Actual number of blocks completed in one hour

\section{Efficiency of the feed block making machine}

The time lost in the operation due to loading, unloading and other factors including failure to achieve the maximum capacity of the machine affect the efficiency (E). Hence, machine efficiency was derived as explained by Smith et al. (1994).

$$
\mathrm{E}(\%)=(\mathrm{AC} / \mathrm{TC}) \times 100
$$

\section{Shelf-life of the Feed Blocks}

Prepared feed blocks were stored under two conditions as packed or unpacked. Packed blocks were covered with polythene covers and sealed immediately after forming blocks. All blocks were stored under proper storage conditions (well ventilated, temperature $28{ }^{\circ} \mathrm{C}$, without any external pest attacks, etc.). To measure the shelf-life of the feed blocks, physical parameters such as colour, odour and appearance were observed under both packed and unpacked conditions during a 30-day storage period.

\section{Experimental Design and Data Analysis}

Durability and post-compression expansion were analysed in completely randomized design (CRD) using SAS ver. 9.0 software (Anon., 2002) and the significant differences in 
means were estimated using Tukey's test at $p=0.05$. Machine performances and the shelf-life parameters were presented by calculating the means.

\section{Results and Discussion}

\section{Designing the Machine}

The fabricated machine is shown in Fig. 3. Power of the hydraulic jack was adequate to press feeding materials. First, the piston was lifted and hold with the support of a pin and a slot in the frame and feed mixture is filled into it. Then, the piston is moved down into the mould using the handle and fixed to the frame using iron pins.

After that, the hydraulic jack is operated manually using its lever to move the mould upward to compress the mixture. As the area of the piston is $0.02546 \mathrm{~m}^{2}$ and the maximum capacity of the hydraulic jack is $500 \mathrm{kN}$, the maximum achievable pressure upon a block is $19265 \mathrm{kN} \mathrm{m}^{-2}$. After keeping the recommended time, the piston is released to remove the completed feed block from the mould.

\section{Specifications of the Machine}

Specifications of the manually operated hydraulic cattle feed block making machine are

Table 3: Specification of the machine

\begin{tabular}{ll}
\hline Component & Dimensions \\
\hline Total height & $150 \mathrm{~cm}$ \\
Total width & $53 \mathrm{~cm}$ \\
Total length & $55 \mathrm{~cm}$ \\
Height of mould & $30 \mathrm{~cm}$ \\
Diameter of mould & $18 \mathrm{~cm}$ \\
Height of piston & $30 \mathrm{~cm}$ \\
Width of piston & $35 \mathrm{~cm}$ \\
Length of handle & $130 \mathrm{~cm}$ \\
Capacity of hydraulic jack & 50 Tonnes \\
\hline
\end{tabular}

presented in Table 3.

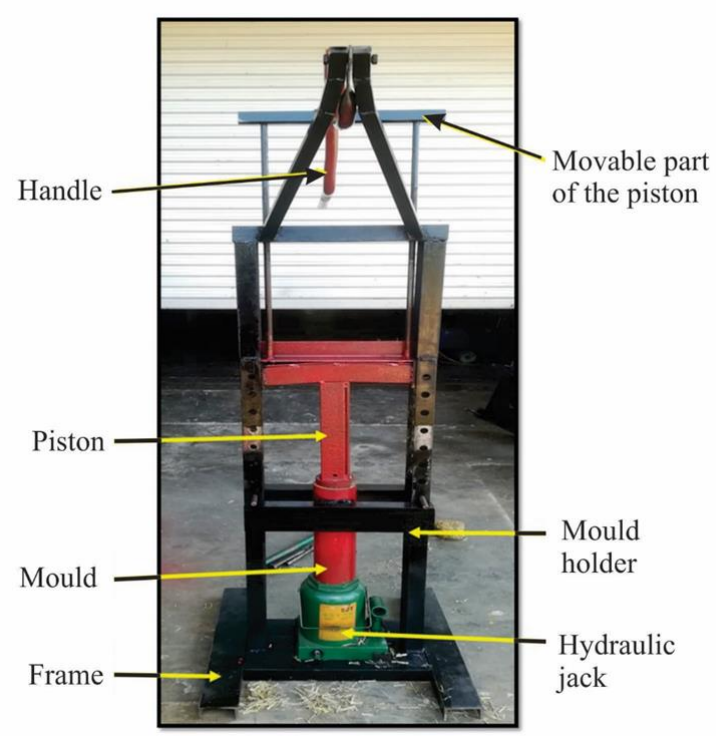

Figure 3: Fabricated cattle feed block making machine

\section{Evaluation of the Machine Performances}

\section{Durability and post-compression expansion}

Table 4 shows the durability and postcompression expansion of feed blocks for different compaction durations and feed mixtures. Durability is the ability of a product to last-long with time without any significant deterioration of its qualities. Higher the durability of feed blocks will be the higher stability of the dimensions (shape) and physical appearance of them which reported to be a good quality parameter. The interaction between feed mixture and compaction time did not significantly affect $(p>0.05)$ on the durability or PEC. However, significantly higher $(p<0.05)$ durability was observed with 15 and 20 minutes compaction times compared to the other two compaction times for mixture 1. However, compaction time was not significantly $(p>0.05)$ affected on durability for the mixture 2. In this study, the durability of the blocks was 
ranged from 73.99 - $99.82 \%$. Similar results were reported by Munasik et al. (2013) for completed feed blocks they produced for dairy cattle. According to Pankaj et al. (2015), the durability of wheat and rice straw-based complete feed blocks were within the range of 70.52 - $78.83 \%$ while rice straw-based blocks reported significantly higher durability.

Compaction time was not significantly $(p>0.05)$ affected on the PEC for mixture 1 or mixture 2. However, numerically lower PEC was reported with 15 and 10 minutes compaction times for mixture 1 and mixture 2, respectively. Pankaj et al. (2015) reported that higher PCE to be a cause for roughages to revert into their original shape after the pressure is removed. Therefore, the lower the PCE better the quality of feed blocks.

Considering the higher durability and the lower PCE of both mixtures, 15 minute is more suitable for preparing feed blocks using the mixture 1 and 10 minutes is recommended for mixture 2.

\section{Machine performance}

The machine performances are important to know how well the machine does the job to which it is designed for, and whether it is profitable or not (Roth et al. 1975). Determining the capacities is a part of the evaluation of the performance of a machine. The terms capacity means the amount of work that can be performed. The capacity of the machine was calculated in two ways, viz., theoretical capacity and actual capacity as described by Hancock et al. (1991).
Theoretical capacity is the amount of work that can be performed per hour without considering any downtime or wastage and with a maximum supply of inputs (Roth et al. 1975). Actual capacity is the actual amount of work performed within one hour considering the time taken for loading, unloading, adjustments, worker fatigue, etc. (Roth et al. 1975).

Table 4: Average durability and post-compression expression percentages of feed mixtures prepared with different compaction durations

\begin{tabular}{ccccc}
\hline $\begin{array}{l}\text { Compaction } \\
\text { duration } \\
\text { (min) }\end{array}$ & \multicolumn{2}{c}{ Mixture 1 } & \multicolumn{2}{c}{ Mixture 2 } \\
\cline { 2 - 5 } & $\begin{array}{c}\text { Durability } \\
\text { (\%) }\end{array}$ & $\begin{array}{c}\text { PEC } \\
\text { (\%) }\end{array}$ & $\begin{array}{c}\text { Durability } \\
\text { (\%) }\end{array}$ & $\begin{array}{c}\text { PEC } \\
\text { (\%) }\end{array}$ \\
\hline 05 & $74.16^{\mathrm{a}}$ & 26.84 & 99.67 & 22.01 \\
10 & $73.99^{\mathrm{a}}$ & 24.36 & 99.82 & 18.64 \\
15 & $99.64^{\mathrm{b}}$ & 23.73 & 94.44 & 18.96 \\
\hline 20 & $99.62^{\mathrm{b}}$ & 24.92 & 98.75 & 21.19 \\
\hline SE & 8.19 & 2.83 & 8.01 & 3.47 \\
\hline
\end{tabular}

a, b means within the same column with different superscripts are significantly different $(p<0.05)$.

Table 5: Average theoretical capacity, actual capacity and efficiency of male and female operators

\begin{tabular}{|c|c|c|c|}
\hline \multirow[b]{2}{*}{ Gender } & \multirow[b]{2}{*}{ Parameter } & \multicolumn{2}{|c|}{ Feed block } \\
\hline & & $\begin{array}{l}\text { Mix. } 1 \text { with } \\
15 \text { min } \\
\text { compaction }\end{array}$ & $\begin{array}{l}\text { Mix .2 with } \\
10 \text { min } \\
\text { compaction }\end{array}$ \\
\hline \multirow[t]{3}{*}{ Male } & $\begin{array}{l}\text { Theoretical } \\
\text { capacity } \\
(\text { blocks h-1) }\end{array}$ & 3.57 & 4.60 \\
\hline & $\begin{array}{l}\text { Actual } \\
\text { capacity } \\
(\text { blocks h-1) }\end{array}$ & 3 & 4 \\
\hline & Efficiency (\%) & 84 & 87 \\
\hline \multirow[t]{3}{*}{ Female } & $\begin{array}{l}\text { Theoretical } \\
\text { capacity } \\
(\text { blocks h-1) }\end{array}$ & 3.53 & 4.56 \\
\hline & $\begin{array}{l}\text { Actual } \\
\text { capacity } \\
(\text { blocks h-1) }\end{array}$ & 3 & 4 \\
\hline & Efficiency (\%) & 85 & 88 \\
\hline
\end{tabular}


The calculated theoretical capacity, actual capacity and efficiency of both male and female operators prepare the feed mixture 1 with 15 minutes compaction and mixture 2 with 10 minutes compaction times are presented in Table 5. According to the results, despite having a difference in theoretical capacities between two blocks, it was almost same for male and female operators. This confirmed that the output (capacity) of the machine does not depend on the gender but determined only by the machine performances. Further, it was an evidence of higher manoeuvrability of the machine.

As presented in Table 5, the average actual capacity was 3 blocks $\mathrm{h}^{-1}$ which prepared with mixture 1 with 15 minutes compaction time and 4 blocks $\mathrm{h}^{-1}$ which prepared with mixture 2 with 10 minutes compaction time. There was no difference by gender (male and female) of the labourer. This indicates the higher manoeuvrability and easy operation of the machine. The capacity of the feed block making machine introduced by the National Engineering Research and Development Centre

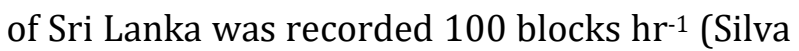
2017). This is due to its less compression time and considerably higher pressure exerted by the hydraulic jack and semi-automatic operational mode. However, it is not affordable for small and medium-scale farmers.

Apart from slight differences, there were no considerable variations in machine efficiencies. Despite showing the higher theoretical capacity by male labourers, efficiency was always less than female labourers as all the labourers have shown the same actual capacity. The operators in the evaluation process used this machine in their first experience in preparation of animal feed blocks. Although it is new to the operators, there is no difference in efficiency. It reveals that to operate this machine, the operators do not have any special skills.

\section{Shelf-life of Feed Blocks}

No visible changes could be found in colour and texture and no fungal growth could be noticed in feed blocks during 30 days of storage under packed condition. According to Kulathunga et al. (2015), the shelf life of prepared feed blocks is higher under polythene pack compared to unpacking. Further, they reported that complete feed blocks can be kept for 30 days without any quality deterioration in polythene packed or unpacked conditions.

\section{Cost of the Machine}

The total cost of materials was 35,000 LKR and cost of labour was 8,000 LKR amounting to a sum of 43,000 LKR per machine, while the price of an animal feed block making machine in the local market is around 500,000 LKR.

\section{Conclusions}

Newly introduced feed block machine is affordable to small scale farmers to produce cattle feed blocks on their own to supply with high-quality nutritious feed for their cattle, as done in commercial level farms. The machine is capable of producing 4 cattle feed blocks per hour with considerably high efficiency. Further, feed blocks produced are highly acceptable concerning their durability and PCE. According to the performance evaluation of the machine, the best compaction time for mixture with $10 \%$ 
molasses is $15 \mathrm{~min}$ and the best compaction time for mixture with $5 \%$ molasses $+5 \%$ cement is 10 min. No safety issues were found in the use of the new machine. Feed blocks can be kept for 1 month in polythene pack without any physical quality deteriorations.

\section{References}

Anon (2012) Crop residue based densified total mixed ration - A user-friendly approach to utilize food crop by-products for ruminant production. FAO Animal Production and Health Paper No. 172. Rome, Italy. 17-25.

Anon (2002) Users Guide Statistics. SAS Institute Inc. Cary. North Carolina. USA.

Hancock J N, Swetnam L D, Benson F J (1991) Calculating farm machinery field capacities. Agricultural Engineering Extension Publication. https://uknowlwdge.uky.edu/aen_reports/20. accessed on 28 April 2020.

Khurmi R S, Gupta J K (2006) A textbook of machine design. Eurasia Publishing House (PVT.) LTD, Ram Nagar, New Delhi. 341-968.

Kulathunga K, Shantha K, Nayananjalie W A D (2015) Preparation of cattle feed blocks using agricultural wastes. Int J Multidisciplinary Studies 2(1):73-80.

Lohan $O$ (1995) Poor quality roughage based complete feed blocks for ruminants. Ann Zootech 44(Suppl. 1): 83-83.

Makkar H P S (2006) Improving animal productivity through meeting nutrient deficiencies with multi-nutrient blocks, enhancing utilization efficiency of alternate feed resources, and controlling internal parasites: $\mathrm{A}$ summary In: Improving Animal Productivity by
Supplementary Feeding of Multinutrient Blocks, Controlling Internal Parasites and Enhancing Utilization of Alternate Feed Resources IAEA, Austria.

Mohammed I D, Baulube M, Adeyinka I A (2007) Multi-nutrient Blocks I: Formulation and Production under a Semi-arid Environment of North East Nigeria. J Biol Sci. 7: 389-392.

Munasik C, Sutrisno I, Anwar S, Prayitno C H (2013) Physical characteristics of pressed complete feed for dairy cattle. Int J Sci Eng. 4(2): 61-65.

Pankaj K S, Chandramoni K K, Kumar S (2015) Effect of feeding wheat and rice straw-based complete feed blocks on nutrients utilization, blood biochemical and growth performance in crossbred calves. Ind J Anim Sci. 86(7): 771776.

Perera B, Jayasuriya M (2008) The dairy industry in Sri Lanka: current status and future directions for a greater role in national development. J National Sci Foundation of Sri Lanka, 36(0), 115.

Roth L O, Crow F R, Mahoney G W A (1975) An introduction to agricultural engineering. AVI Publishing Company Inc. Westport, USA.

Santhiralingam S, Sinniah J (2018) A study on making complete feed blocks for cattle with different combination of fodder grasses and agricultural wastes. Int J Sci and Res Pub. 8(9): 650-656.

Smith D W, Sims B G, O'Neill D H (1994) Testing and evaluation of agricultural machinery and equipment. Food and Agriculture Organization of the United Nations, Rome. 47-48. 
Silva S A P S (2017) Development of a solid feed block forming machine for cattle. (Master's thesis) Department of Mechanical Engineering, University of Moratuwa, Sri Lanka.

Singh K K, Das M M, Samanta V, Kundu S S (2007) Comparative growth performance of crossbred calves fed on complete diet in mash or block form. Indi J Anim Sci 77(10): 10211025 . 